\title{
Studies on the Kinetics of Oxidation of 4-Oxo-4-phenylbutanoic Acid by Benzimidazolium Fluorochromate in the Presence of Oxalic Acid in Acetic Acid-Water Medium
}

I. VANNAMUTHU ${ }^{1,2}$, V. SALEEM MALIK
S. SYED SHAFI $^{3}$ and S. SHEIK MANSOOR

${ }^{1}$ Department of Chemistry, C. Abdul Hakeem College (Autonomous), Melvisharam - 632 509, Tamil Nadu, India

${ }^{2}$ Department of Chemistry, Periyar Government Arts College, Cuddalore - 607001, Tamil Nadu, India

${ }^{3}$ Department of Chemistry, Thiruvalluvar University, Serkadu, Vellore - 632115, Tamil Nadu, India smansoors2000@yahoo.co.in

Received 23 February 2015/ Accepted 18 March 2015

\begin{abstract}
Kinetics of oxidation of 4-oxo-4-phenyl butanoic acid (4-oxo acid) by benzimidazolium fluorochromate (BIFC) in acetic acid-water medium with perchloric acid in the presence of oxalic acid (OA) has been studied. The reaction is first order each in [BIFC], [4-oxo acid] and $\left[\mathrm{H}^{+}\right]$. The reaction has been found to be catalyzed by $\mathrm{H}^{+}$ions. The reaction rate increased remarkably with the increase in the proportion of acetic acid in the solvent medium. Various thermodynamic parameters have been determined at different acetic acid-water composition. A suitable mechanism has been proposed.
\end{abstract}

Keywords: 4-Oxo acid, Kinetics, Oxidation, Benzimidazolium fluorochromate, Oxalic acid

\section{Introduction}

Chromium compounds have been used in aqueous and non-aqueous medium for the oxidation of a variety of organic compounds. Chromium(VI) is established as a versatile oxidant for the oxidation of a variety of organic compounds ${ }^{1}$. Chromium(VI) as chromate or dichromate is highly soluble in water, and is reported to be highly toxic, there are continued interest in the development of new $\mathrm{Cr}(\mathrm{VI})$ reagents for the effective and selective oxidation of organic substrates, under mild conditions. A number of new $\mathrm{Cr}(\mathrm{VI})$ containing compounds like tripropylammonium fluorochromate ${ }^{2}$, pyridinium fluorochromate ${ }^{3}$, tetraethylammonium chlorochromate ${ }^{4}$, tributylammonium chlorochromate ${ }^{5}$, imidazolium fluorochromate ${ }^{6}$ and pyridinium dichromate ${ }^{7}$ have been used to study the kinetics and mechanism of various organic compounds. 
Benzimidazolium fluorochromate is also one such oxidant developed recently ${ }^{8-13}$. It is a more efficient and stronger oxidizing agent. This new compound is more efficient for quantitative oxidation of several organic substrates and has certain advantages over similar oxidizing agents in terms of the amount of oxidant and solvent required, short reaction times and high yields. Among the different chelating agents ${ }^{14-19}$ that promote $\mathrm{Cr}(\mathrm{VI})$ oxidation of different types of organic substrate, oxalic acid is quite important ${ }^{20-23}$.

Extensive studies on the mechanism of oxidation of 4-oxo acids by different oxidants have been the subject of study by various workers ${ }^{24-31}$. Recently we have studied the oxidation of 4-oxo-4-phenylbutanoic acid by tripropylammonium fluorochromate in aqueous acetic acid medium ${ }^{32}$. However, no detailed kinetic study of oxidation of 4-oxo-4-phenylbutanoic acid by BIFC, a $\mathrm{Cr}(\mathrm{VI})$ reagent in the presence of oxalic acid have so far been attempted. Here we studied the kinetics of oxidation of 4-oxo-4-phenylbutanoic acid by BIFC in the presence of oxalic acid. Mechanistic aspects are also discussed.

\section{Experimental}

Benzimidazole and chromium trioxide were obtained from Fluka (Buchs, Switzerland). Acetic acid was purified by standard method and the fraction distilling at $118{ }^{\circ} \mathrm{C}$ was collected. Perchloric acid was used as the source of hydrogen ion.

\section{Preparation of 4-oxo-4-phenylbutanoic acid}

The 4-oxo-4-phenylbutanoic acid was synthesized by the Friedel-Craft's reaction between succinic anhydride and benzene in the presence of anhydrous aluminium chloride ${ }^{24}$.

\section{Preparation of benzimidazolium fluorochromate}

Benzimidazolium fluorochromate has been prepared from benzimidazole, $40 \%$ hydrofluoric acid and chromium trioxide in the molar ratio $1: 1.3: 1$ at $0{ }^{\circ} \mathrm{C}$ as reported in the literature ${ }^{8}$.

\section{Kinetic measurements}

The pseudo-first-order conditions were attained by maintaining a large excess ( x 15 or more) of 4-oxo acid over BIFC. The solvent was $50 \%$ acetic acid-50\% water (v/v), unless specified otherwise. The reactions were followed, at constant temperatures $( \pm 0.01 \mathrm{~K})$, by monitoring the decrease in [BIFC] spectrophotometrically at $364 \mathrm{~nm}$ using UV-Vis spectrophotometer, Shimadzu UV-1800 model. The pseudo-first-order rate constant $k_{o b s}$, was evaluated from the linear ( $\mathrm{r}=0.990$ to 0.999$)$ plots of $\log$ [BIFC] against time for up to $80 \%$ reaction. The second order rate constant $k_{2}$, was obtained from the relation $k_{2}=k_{o b s} /$ [4-oxo acid].

\section{Product analysis}

Product study was made under mineral acid catalysed condition in 4-oxo-4-phenylbutanoic acid. Keeping the concentration of BIFC in excess over [4-oxo acid], the two solutions were mixed together in $50 \%$ acetic acid-50\% water $(\mathrm{v} / \mathrm{v})$. The reaction mixture was allowed to go to completion by keeping it in a thermostat at $303 \mathrm{~K}$ for $24 \mathrm{~h}$ to ensure the completion of the reaction. The product was obtained which had melting point of $121{ }^{\circ} \mathrm{C}$. It was dissolved in benzene and a careful TLC analysis was done with benzoic acid and 4-oxo-4-phenyl butanoic acid as references. Only one spot corresponding to benzoic acid was obtained. 


\section{Stoichiometric studies}

The stoichiometric studies for the oxidation of 4-oxo acid by BIFC were carried out with oxidant in excess. The solvent composition $50 \%$ acetic acid- $50 \%$ water $(\mathrm{v} / \mathrm{v})$ and $\left[\mathrm{H}^{+}\right]$were maintained as in the corresponding rate measurements. The temperature was maintained at $303 \mathrm{~K}$. The 4-oxo acid and BIFC were mixed in the ratio 1:4, 1:5, 1:6 and were allowed to react for $24 \mathrm{~h}$ at $303 \mathrm{~K}$. The concentration of unreacted BIFC was determined. $\Delta[\mathrm{BIFC}]$ was calculated. The stoichiometry was calculated from the ratio between [4-oxo acid] and [BIFC]. The estimation of unreacted BIFC showed that 1 mol of BIFC reacts with 1 mol of 4-oxo-4-phenylbutanoic acid.

\section{Results and Discussion}

\section{Order of reaction}

The reactions were found to be first order with respect to BIFC. The individual kinetic runs were strictly first order to BIFC. Further, the pseudo-first-order rate constants do not depend on the initial concentration of BIFC. The reaction rate increases with an increase in the concentration of substrate (Table 1). Further, the plot of $k_{\text {obs }}$ versus [4-oxo acid] is excellently linear passing through origin (Figure 1). Linear plots of $\log k_{1}$ vesus $\log$ [4-oxo acid] with unit slope also demonstrates the first order dependence of the rate on [4-oxo acid] (Figure 2).

Table 1. Rate constants for the oxidation of 4-oxo-4-phenylbutanoic acid by BIFC in aqueous acetic acid medium in the presence of oxalic acid at $303 \mathrm{~K}^{\mathrm{a}}$

\begin{tabular}{ccccc}
\hline $\begin{array}{c}10^{3}[\mathrm{BIFC}] \\
\mathrm{mol} \mathrm{dm}^{-3}\end{array}$ & $\begin{array}{c}10^{2}[4-\text { oxo acid }] \\
\mathrm{mol} \mathrm{dm}^{-3}\end{array}$ & {$\left[\mathrm{H}^{+}\right] \mathrm{mol} \mathrm{dm}^{-3}$} & $\begin{array}{c}10^{3}[\mathrm{OA}] \\
\mathrm{mol} \mathrm{dm}^{-3}\end{array}$ & $\begin{array}{c}10^{4} \mathrm{k}_{1}{ }^{\mathrm{b}} \\
\mathrm{s}^{-1}\end{array}$ \\
\hline 1.2 & 2.0 & 0.18 & 0.0 & 16.22 \\
1.2 & 2.0 & 0.18 & 2.0 & 17.64 \\
1.2 & 2.0 & 0.18 & 4.0 & 19.08 \\
1.2 & 2.0 & 0.18 & 6.0 & 20.44 \\
1.2 & 2.0 & 0.18 & 8.0 & 21.88 \\
1.2 & 2.0 & 0.18 & 10.0 & 23.24 \\
0.8 & 2.0 & 0.18 & 6.0 & 20.38 \\
1.6 & 2.0 & 0.18 & 6.0 & 20.48 \\
2.0 & 2.0 & 0.18 & 6.0 & 20.36 \\
2.4 & 2.0 & 0.18 & 6.0 & 20.40 \\
1.2 & 1.0 & 0.18 & 6.0 & 10.44 \\
1.2 & 1.5 & 0.18 & 6.0 & 15.22 \\
1.2 & 2.5 & 0.18 & 6.0 & 25.30 \\
1.2 & 3.0 & 0.18 & 6.0 & 30.48 \\
1.2 & 2.0 & 0.10 & 6.0 & 11.32 \\
1.2 & 2.0 & 0.14 & 6.0 & 15.88 \\
1.2 & 2.0 & 0.22 & 6.0 & 25.16 \\
1.2 & 2.0 & 0.26 & 6.0 & 29.48 \\
1.2 & 2.0 & 018 & 6.0 & $20.36^{\mathrm{c}}$ \\
1.2 & 2.0 & 018 & 6.0 & $18.96^{\mathrm{d}}$ \\
\hline
\end{tabular}

${ }^{a}$ As determined by a spectrophotometric technique following the disappearance of oxidant $10^{2}$ [4-oxo acid $]=2.0 \mathrm{~mol} \mathrm{dm}^{-3} ; 10^{3}[\mathrm{BIFC}]=1.2 \mathrm{~mol} \mathrm{dm}^{-3} ;\left[\mathrm{H}^{+}\right]=0.18 \mathrm{~mol} \mathrm{dm}{ }^{-3}$, Solvent composition: $50 \%$ Acetic acid $-50 \%$ Water $(\mathrm{v} / \mathrm{v})$, ${ }^{b}$ Estimated from pseudo-first order plots over $80 \%$ reaction, ${ }^{c}$ Contained $0.001 \mathrm{~mol} \mathrm{dm}^{-3}$ acrylonitrile. ${ }^{d}$ In the presence of $0.003 \mathrm{~mol} \mathrm{dm} \mathrm{m}^{-3} \mathrm{Mn}(\mathrm{II})$ 


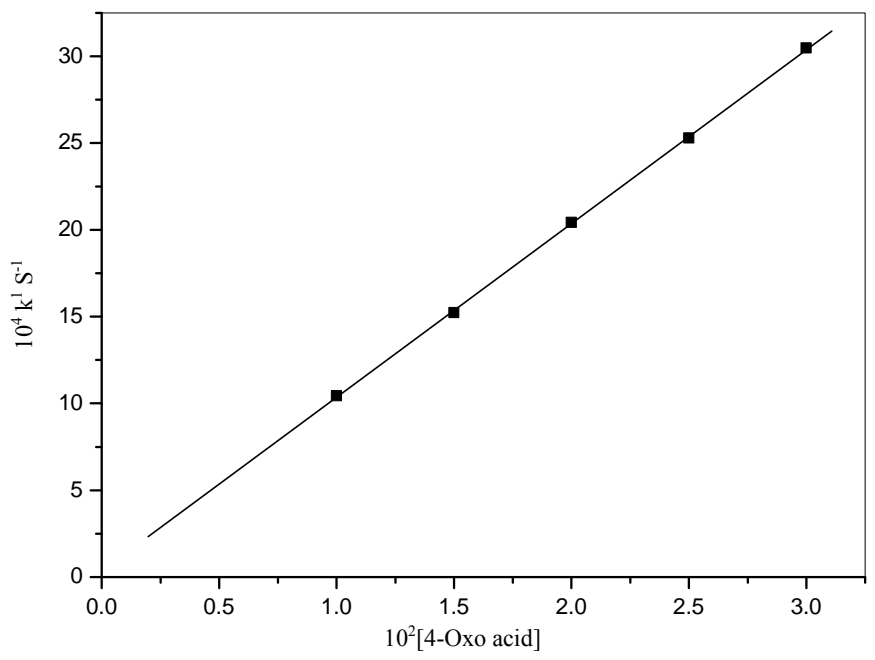

Figure 1. Showing direct plot of 4-oxo acid for the oxidation of 4-oxo acid by BIFC in the presence of oxalic acid

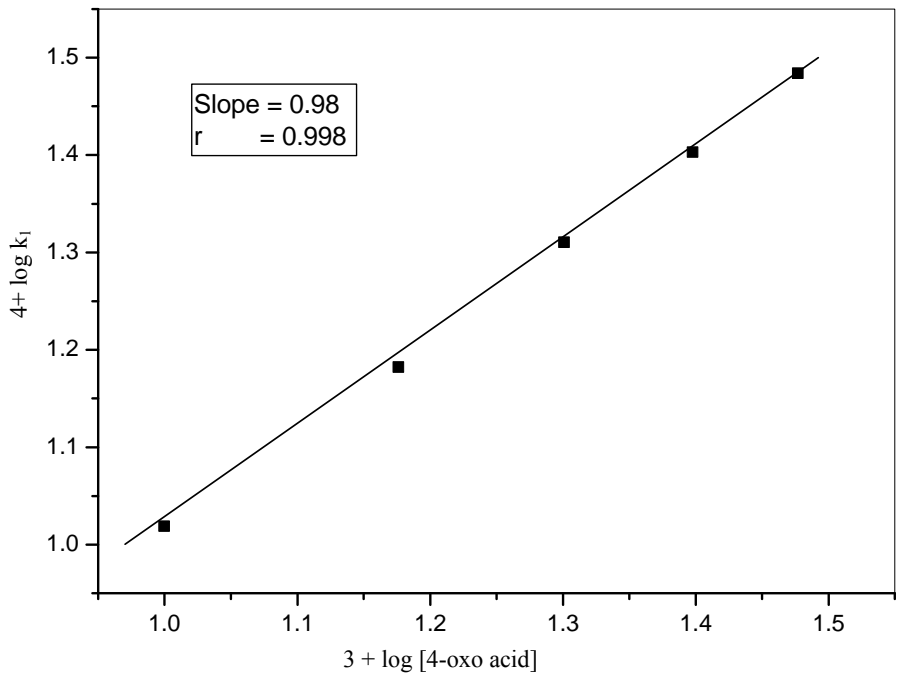

Figure 2. Showing order plot of 4-oxo acid for the oxidation of 4-oxo acid by BIFC in the presence of oxalic acid

\section{Effect of varying perchloric acid concentration}

Perchloric acid has been used as a source of $\mathrm{H}^{+}$in reaction medium. The concentration of $\mathrm{H}^{+}$ was varied in the range 0.10 to $0.26 \mathrm{~mol} \mathrm{dm}^{-1}$ keeping all other reactant concentration as constant at $303 \mathrm{~K}$ and the rates were measured (Table 1). The acid catalysed nature of this oxidation is confirmed by an increase in the rate on the addition of $\mathrm{H}^{+}$. The double logarithmic plot of $k_{1}$ versus $\left[\mathrm{H}^{+}\right]$is excellently linear (Figure 3 ) with a slope value very equal to one, establishing that the reaction is first-order with respect to $\left[\mathrm{H}^{+}\right]$. BIFC may become protonated in the presence of acid and the protonated BIFC may function as an effective oxidant. 


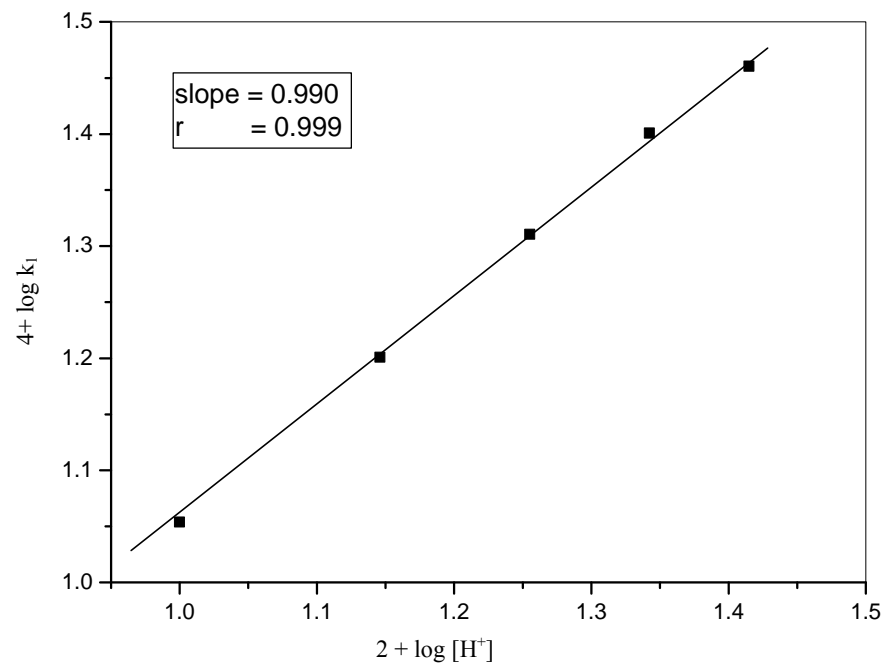

Figure 3. Showing order plot of perchloric acid for the oxidation of 4-oxo acid by BIFC in the presence of Oxalic acid

The acid-catalysis may well be attributed to a protonation of BIFC to give a stronger oxidant and electrophile.

$$
\mathrm{O}_{2} \mathrm{CrFO}^{-} \mathrm{BIH}^{+}+\mathrm{H}^{+} \rightleftharpoons(\mathrm{OH}) \mathrm{OCrFO}^{-} \mathrm{BIH}^{+}
$$

The formation of a protonated $\mathrm{Cr}(\mathrm{VI})$ species has earlier been postulated in the reactions of structurally similar PFC $^{33}$.

\section{Effect of acrylonitrile and $\mathrm{MnSO}_{4}$}

The reaction did not promote polymerization of acrylonitrile indicating the absence of free radicals (Table 1). However, the addition of $\mathrm{Mn}(\mathrm{II})\left(0.003 \mathrm{~mol} \mathrm{dm}{ }^{-3}\right)$, in the form of $\mathrm{MnSO}_{4}$ retards the rate of oxidation (Table 1). This indicates the involvement of $\mathrm{Cr}(\mathrm{IV})$ intermediate in the oxidation of 4-oxo acid by $\mathrm{Cr}(\mathrm{VI})$ reagent and confirms the two electron transfer process in the reaction. $\mathrm{Mn}(\mathrm{II})$ ion reduces $\mathrm{Cr}(\mathrm{IV})$ formed to $\mathrm{Cr}(\mathrm{III})$. In the absence of $\mathrm{Mn}$ (II) ion, formed $\mathrm{Cr}(\mathrm{IV})$ reduces $\mathrm{Cr}(\mathrm{VI})$ to $\mathrm{Cr}(\mathrm{V})$ and the oxidation of 4-oxo acid by $\mathrm{Cr}(\mathrm{V})$ is fast ${ }^{34}$. The decrease in the rate of $\mathrm{Cr}(\mathrm{VI})$ reduction on the addition of $\mathrm{Mn}(\mathrm{II})$ has been attributed to the removal of $\mathrm{Cr}(\mathrm{IV})$ by reaction ${ }^{35}$ with $\mathrm{Mn}(\mathrm{II})$.

\section{Effect of solvent polarity on reaction rate}

The oxidation of 4-oxo-4-phenylbutanoic acid in the presence of oxalic acid has been studied in the binary mixture of acetic acid and water as the solvent medium. For the oxidation of 4-oxo-4-phenylbutanoic acid, the reaction rate increased remarkably with the increase in the proportion of acetic acid in the solvent medium. These results are presented in Table 2. The plot of $\log k_{1}$ versus 1/D (dielectric constant) is linear with positive slope suggesting the presence of either dipole-dipole or ion-dipole type of interaction between the oxidant and the substrate (Figure 4).

$\mathrm{Amis}^{36}$ holds the view that in an ion-dipole reaction involving a positive ionic reactant, the rate would decrease with increasing dielectric constant of the medium and if the reactant were to be a negatively charged ion, the rate would increase with the increasing dielectric constant. In this case there is a possibility of a positive ionic reactant, as the rate decreases 
with the increasing dielectric constant of the medium. Due to the polar nature of the solvent, transition state is stabilized, i.e., the polar solvent molecules surround the transition state and result in less disproportion.

Table 2. Pseudo-first order rate constants for the oxidation of 4-oxo-4-phenylbutanoic acid by BIFC at various percentage of acetic acid-water medium in the presence of oxalic acid at various temperatures

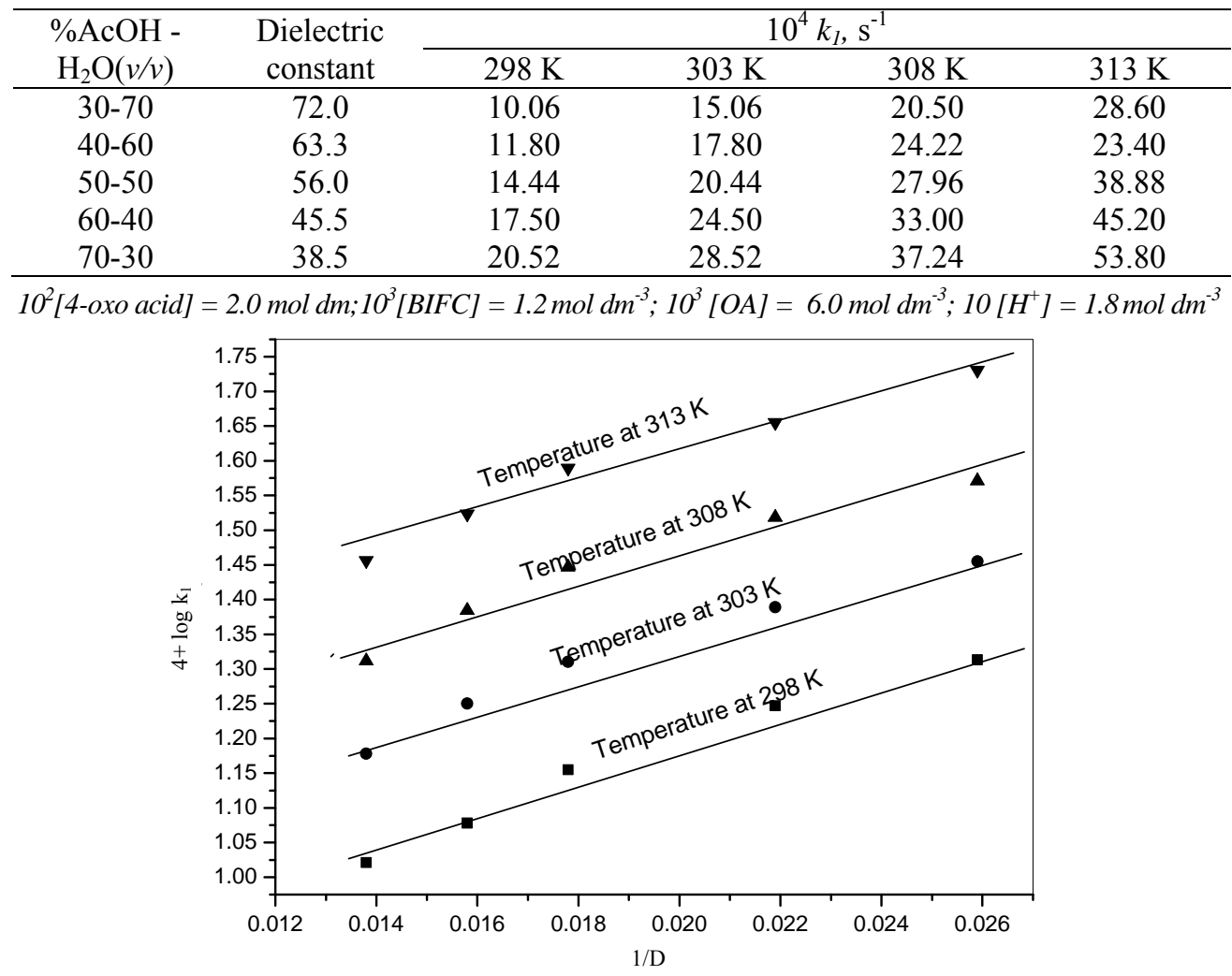

Figure 4. Plot of $1 / \mathrm{D}$ against $\log k_{1}$ showing effect of solvent polarity at various temperatures in the presence of oxalic acid

In the present study, the significant rate enhancement with the lowering of dielectric constant of the solvent medium may be attributed to the enolisation of the keto acid group in the 4-oxo-4-phenylbutanoic acid. The enolisation of the keto group of the oxo acid is facilitated by the increase in percentage of acetic acid in the solvent medium and this may also favors the rate enhancement.

\section{Rate of enolisation by bromination method}

It has been reported earlier in the case of oxidation of keto compounds that the oxidation proceeds via enolisation of the keto compounds. The rate of enolisation of keto compound is faster than the rate of oxidation. The reactive species of the substrate may be determined by enolisation, which is an acid as well as base catalysed reaction and proceeds by a concerted or push-pull mechanism. The rate of enolisation was determined by bromination method for the system under investigation. 
The order of bromination reaction with respect to the 4-oxo-4-phenylbutanoic acid, bromine and $\mathrm{H}^{+}$has been determined. These data indicate that the bromination of the 4-oxo4-phenylbutanoic acid is first order each with respect to the substrate and $\mathrm{H}^{+}$ion but zero order with respect to bromine.

\section{Thermodynamic parameters}

The kinetics of oxidation of 4-oxo acid in the presence of oxalic acid is studied at four different temperatures viz., 298, 303, 308 and $313 \mathrm{~K}$ at various percentage of acetic acidwater medium. The second order rate constants were calculated (Table 3). The Arrhenius plot of $\log k_{2}$ versus $1 / \mathrm{T}$ is found to be linear. The enthalpy of activation, entropy of activation and free energy of activation were calculated from $k_{2}$ at 298, 303, 308 and $313 \mathrm{~K}$ using the Eyring relationship by the method of least square and presented in Table 3 . The least square method gives the values and standard errors of enthalpy and entropy of activation respectively. Statistical analysis of the Eyring equation clearly confirms that the standard errors of $\Delta \mathrm{H}^{\#}$ and $\Delta \mathrm{S}^{\#}$ correlate ${ }^{37}$.

Table 3. Second order rate constants and activation parameters for the oxidation of 4-oxo-4phenylbutanoic acid by BIFC at various percentage of acetic acid-water medium in the presence of oxalic acid

\begin{tabular}{ccccccccc}
\hline $\begin{array}{c}\text { \%AcOH - } \\
\mathrm{H}_{2} \mathrm{O}(v / v)\end{array}$ & \multicolumn{3}{c}{$10^{3} \mathrm{k}_{2} \mathrm{dm}^{3} \mathrm{~mol}^{-1} \mathrm{~s}^{-1}$} & $\begin{array}{c}\mathrm{E}_{a} \\
\mathrm{kJmol}^{-1}\end{array}$ & $\begin{array}{c}-\Delta \mathrm{S}^{\#} \\
\mathrm{JK}^{-1} \mathrm{~mol}^{-1}\end{array}$ & $\begin{array}{c}\Delta \mathrm{H}^{\#} \\
\mathrm{kJmol}^{-1}\end{array}$ & $\begin{array}{c}\Delta \mathrm{G}^{\#} \mathrm{kJmol}^{-1} \\
\text { at 303 K}\end{array}$ \\
\cline { 2 - 9 } & $298 \mathrm{~K}$ & $303 \mathrm{~K}$ & $308 \mathrm{~K}$ & $313 \mathrm{~K}$ & & & & \\
\hline $30-70$ & 5.25 & 7.53 & 10.25 & 14.30 & 51.31 & $105.48 \pm 2.4$ & $48.82 \pm 0.8$ & $80.78 \pm 1.5$ \\
$40-60$ & 5.98 & 8.90 & 12.11 & 16.70 & 52.46 & $100.31 \pm 3.2$ & $49.97 \pm 1.1$ & $80.36 \pm 2.0$ \\
$50-50$ & 7.14 & 10.22 & 13.98 & 19.44 & 51.50 & $101.45 \pm 2.4$ & $48.44 \pm 0.8$ & $79.18 \pm 2.0$ \\
$60-40$ & 8.83 & 12.25 & 16.50 & 22.60 & 48.25 & $111.42 \pm 1.5$ & $45.76 \pm 0.5$ & $79.52 \pm 1.0$ \\
$70-30$ & 10.28 & 14.26 & 18.62 & 26.90 & 48.82 & $108.53 \pm 3.6$ & $46.33 \pm 1.2$ & $79.21 \pm 2.2$ \\
\hline
\end{tabular}

$10^{2}[4-\mathrm{oxo}]=2.0 \mathrm{~mol} \mathrm{dm}-10^{3}[\mathrm{BIFC}]=1.2 \mathrm{~mol} \mathrm{dm}^{-3} ; 10^{3}[\mathrm{OA}]=6.0 \mathrm{~mol} \mathrm{dm}^{-3} ; 10\left[\mathrm{H}^{+}\right]=1.8 \mathrm{~mol} \mathrm{dm}^{-3}$

\section{Mechanism of oxidation}

A probable mechanism for the oxidation of 4-oxo-4-phenylbutanoic acid in the presence of oxalic acid by BIFC has been proposed based on the experimental results and in analogy with the oxidation of oxo compounds with the other oxidants. The results obtained in the kinetic study are briefly summarized below: The reaction is first order each with respect to the 4-oxo-4-phenylbutanoic acid, BIFC and $\mathrm{H}^{+}$ion. The linear increase in the reaction rate with the increase in $\left[\mathrm{H}^{+}\right]$ion is attributed to the formation of protonated $\mathrm{BIFC}$ i.e. $\mathrm{BIFCH}^{+}$and to the enolisation of the 4-oxo-4-phenylbutanoic acid. The formation of $\mathrm{BIFCH}^{+}$ion and the enolisation of the 4-oxo-4-phenylbutanoic acid is facilitated at lower dielectric constant of the medium. The rate of enolisation is found to be greater than the rate of oxidation. The course of oxidation does not involve any free radical intermediate.

As reported previously ${ }^{23}$, Oxalic acid readily form complex $\left(\mathrm{C}_{1}\right)$ with $\mathrm{Cr}(\mathrm{VI})$. In the next step, the complex reacts with the substrate to form a ternary complex $\left(\mathrm{C}_{2}\right)$. This ternary complex $\left(\mathrm{C}_{2}\right)$ undergoes redox decomposition by two electron transfer within the cyclic transition state in a rate-determining step involving simultaneous rupture of $\mathrm{C}-\mathrm{C}$ and $\mathrm{C}-\mathrm{H}$ bonds to give a benzoic acid and the $\mathrm{Cr}(\mathrm{IV})-\mathrm{OA}$ complexes. Considering these facts and findings a suitable mechanism has been proposed for the oxidation (Scheme 1). 


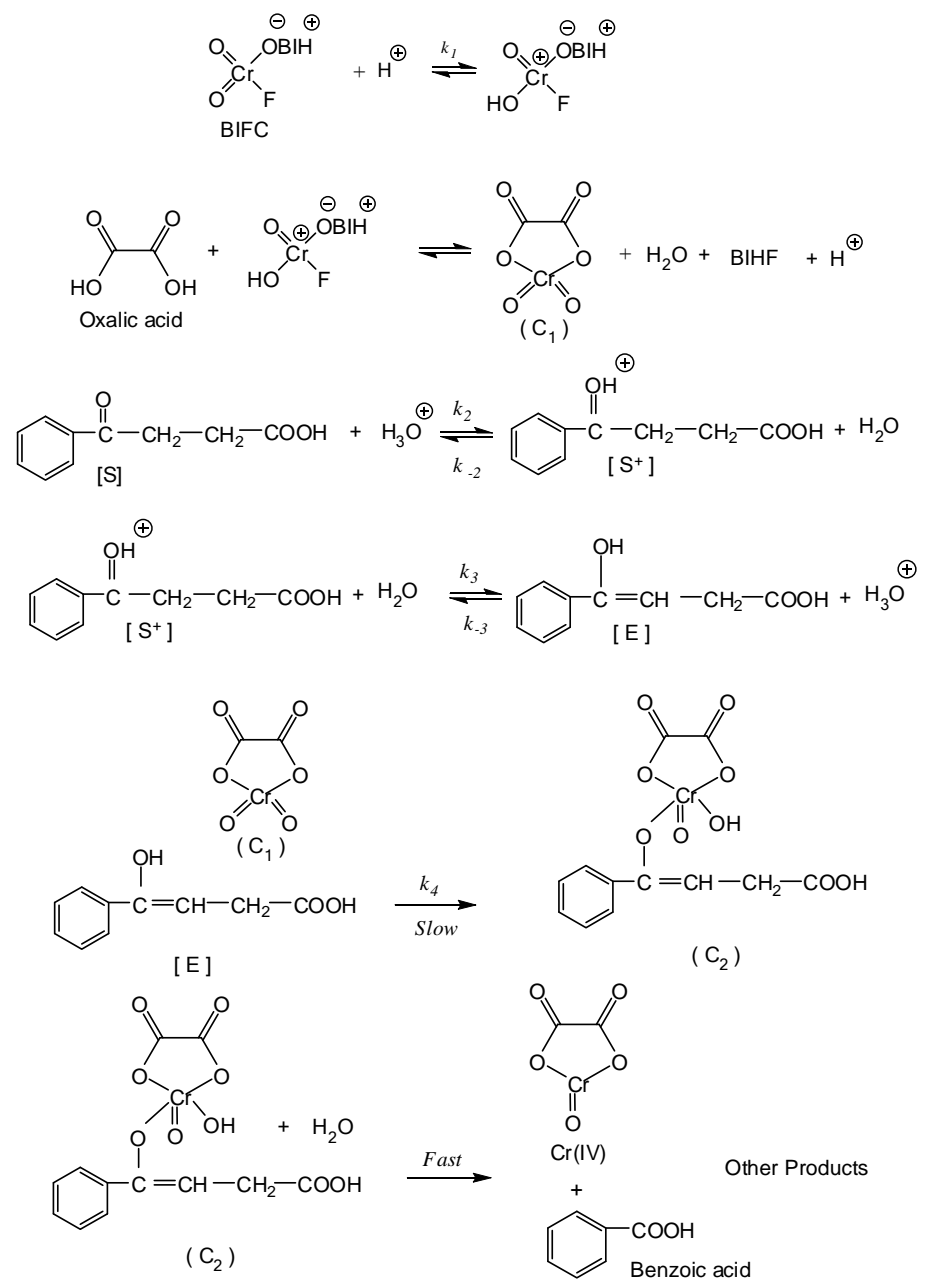

Scheme 1. Mechanism of oxidation of 4-oxo acid in the presence of oxalic acid

\section{Conclusion}

The kinetics of oxidation of 4-oxo-4-phenylbutanoic acid has been investigated in aqueous acetic acid medium by spectrophotometrically at $303 \mathrm{~K}$ in the presence of oxalic acid. The reaction does not show the polymerization, which indicates the absence of free radical intermediate in the oxidation. The oxidation of 4-oxo-4-phenylbutanoic acid has been conducted at four different temperatures at various percentage of acetic acid-water medium in the presence of oxalic acid. The lowering of dielectric constant of reaction medium increases the reaction rate significantly.

\section{References}

1. Patel S and Mishra B K, Tetrahedron, 2007, 63(21), 4367-4406;

DOI:10.1016/j.tet.2007.02.073

2. Shanthi S and Mansoor S S, Chem Sci Trans., 2015, 4(1), 213-221;

DOI: $10.7598 /$ cst2015.974 
3. Hiran B L, Khuntwal J, Malkani R K and Singh D, Arab J Chem., 2011; DOI:10.1016/j.arabjc.2011.05.017

4. Swami P, Yajurvedi D, Mishra P and Sharma P K, Int J Chem Kinet., 2010, 42(1), 50 -55; DOI:10.1002/kin.20466

5. Mansoor S S and Shafi S S, React Kinet Mech Cat., 2010, 100, 21-31; DOI:10.1007/s11144-010-0148-4

6. Alhaji N M I, Shajahan A and Ayyadurai G K, Chem Sci Trans., 2013, 2(2), 429434; DOI:10.7598/cst2013.376

7. Harith H, Hiran B L and Joshi S N, Chem Sci Trans., 2015, 4(1), 49-58; DOI:10.7598/cst2015.955

8. Sivamurugan V, Rajkumar G A, Arabindoo B and Murugesan V, Indian J Chem., 2005, 44A, 144-147.

9. Dharmaraja J, Krishnasamy K and Shanmugam M, E-J Chem., 2008, 5, 754-760.

10. Mansoor S S, Asian J Chem., 2010, 22(10), 7591-7600.

11. Mansoor S S, Shafi S S and Ahmed S Z, Arab J Chem., 2011;

DOI:10.1016/j.arabjc.2011.06.026

12. Mansoor S S and Shafi S S, Arab J Chem., 2014, 7(2), 171-176; DOI:10.1016/j.arabjc.2010.10.020

13. Asghar B H, Mansoor S S, Hussain A M, Malik V S, Aswin K and Sudhan S P N, Arab J Chem., 2013; DOI:10.1016/j.arabjc.2013.07.043

14. Meenakshisundaram S and Markkandan R, Transit Met Chem., 2004, 29(3), 308314; DOI:10.1023/B:TMCH.0000020374.24384.38

15. Meenakshisundaram S and Sarathi N, Transit Met Chem., 2006, 31(5), 569-574; DOI:10.1007/s11243-006-0018-0

16. Saha B, Islam M and Das A K, Prog React Kinet Mech., 2005, 30, 145.

17. Khan Z, Masan S, Raju and Kabir-ud-Din, Transit Met Chem., 2003, 28(8), 881-887; DOI:10.1023/A:1026303415289

18. Islam M, Saha B, Das A K, Int J Chem Kinet., 2006, 38(9), 531- 539; http://dx.doi.org/10.1002/kin.20181

19. Das A K, Coord Chem Rev., 2004, 248(1-2), 81- 99; DOI:10.1016/j.cct.2003.10.012

20. Balasubramanian S, Nagarajan K, Sundaram S and Venkatasubramanian N, Indian J Chem., 1980, 19A, 81.

21. Sarada N C and Reddy I A K, J Indian Chem Soc., 1993, 70, 35 - 39.

22. Meenakshisundaram S P, Gopalakrishnan M, Nagarajan S and Sarathi N, Catal Commun., 2007, 8(4), 713 - 718; DOI:10.1016/j.catcom.2006.08.033

23. Vanangamudi $G$ and Srinivasan S, J Chem., 2009, 6(3), 920 - 927; DOI:10.1155/2009/242743

24. Sikkandar G and Ahmed K A B, Indian J Chem., 1999, 38A, 183 - 186.

25. Kavitha S, Pandurangan A and Alphonse I, Indian J Chem., 2005, 44A, 715 - 718.

26. Farook N A M, J Iranian Chem. Soc., 2006, 3, 378-386; DOI:10.1007/BF03245962

27. Farook N A M, J Solution Chem., 2007, 36(3), 345-356; DOI:10.1007/s10953-0069116-z

28. Reddy C S and Manjari P S, Indian J Chem., 2010, 49A, 418 - 424.

29. Farook N A M and Dameem G A S, J Chem., 2011, 8(2), 479-482; DOI:10.1155/2011/173749

30. Farook N A M and Dameem G A S, J Chem, 2011, 8(2), 561-564; DOI:10.1155/2011/697973 
31. Farook N A M, Manochitra S and Banu A A, J Solution Chem., 2013, 42(1), 239250; DOI:10.1007/s10953-012-9942-0

32. Yogananth Aand Mansoor S S, Orient J Chem., 2015, 31(1), 17-23

33. Sharma V, Sharma P K and Banerji K K, J Chem Research(S), 1996, 290-291.

34. Karunakaran C and Suesh S, J Phys Org Chem., 2004, 17(1), 88 -93; DOI:10.1002/poc.699

35. Khan Z, Dar M Y and Babe P S S, Indian J Chem., 2004, 42A, 1060 - 1065.

36. Amis E S, Solvent Effects on Reaction Rates and Mechanisms. Academic Press, New York, 1967, 42.

37. Lente G, Fabian I and Poe A J, New J Chem., 2005, 29, 759-760;

DOI:10.1039/B501687H 